\title{
CXCL16 signaling mediated macrophage effects on tumor invasion of papillary thyroid carcinoma
}

\author{
Sun Wook Cho', Young A Kim², Hyun Jin Sun', Ye An Kim¹, Byung-Chul Oh${ }^{3}$, Ka Hee Yi', \\ Do Joon Park' and Young Joo Park ${ }^{1}$ \\ ${ }^{1}$ Department of Internal Medicine, Seoul National University College of Medicine, 101 Daehak-ro, Jongno-gu, \\ Seoul 03080, South Korea \\ ${ }^{2}$ Department of Pathology, Borame Medical Center 20, Boramae-ro 5-gil, Dongjak-gu, Seoul 07061, South Korea \\ ${ }^{3}$ Lee Gil Ya Cancer and Diabetes Institute, Gachon University Graduate School of Medicine, 155 Gatbeol-ro, \\ Yeonsu-ku, Incheon 406-840, Korea
}

\author{
Correspondence \\ should be addressed \\ to Y J Park \\ Email \\ yjparkmd@snu.ac.kr
}

\begin{abstract}
Macrophages in tumor microenvironment have pivotal roles in tumor growth, metastasis, and angiogenesis. We investigated the interacting mechanism of macrophage actions in human papillary thyroid cancer (PTC). Co-cultures of macrophage/PTC significantly increased the cancer cell migration potentials, compared with the PTC culture alone. Treatment of conditioned medium (CM) of macrophage/PTC co-cultures enhanced cell invasions in 3D invasion assay. Cytokine array analysis demonstrated that CM of macrophage/PTC co-cultures contained a high level of CXCL16, while it was not found in CM of PTC culture alone. Treatment with CXCL16 enhanced the cell migration potentials in PTC cells, and blocking CXCL16 signaling using anti-CXCL16 antibody or metalloproteinase inhibitor (TAPI2) attenuated macrophagemediated enhancement of PTC cell migration potentials. In PTC cells, CXCL16 treatment or co-cultures with macrophages increased Akt phosphorylation, and these macrophagedependent increases of Akt phosphorylation was inhibited by anti-CXCL16 antibody. Moreover, Akt inhibitor attenuated macrophage-mediated increases of PTC cell migration potential. In macrophages, treatment of macrophage/PTC co-cultured CMs up-regulated CD163, II10, and CD206, which were attenuated by anti-CXCL16 antibody treatment. Finally, CXCR6 and CXCL16 expressions were evaluated by immunohistochemical staining with a thyroid tissue microarray including 136 PTC. CXCR6 expressions showed positive correlation with the density of CD163 ${ }^{+}$ macrophages and associated with lymph node metastasis. In conclusion, CXCL16 signaling partly mediated macrophage actions on PTC tumor cell invasion and also changed the macrophage phenotypes into M2-macrophages in PTC tumor microenvironment. These data suggested that CXCL16 signaling, a bidirectional player in macrophage-associated tumor microenvironment, might be a potential therapeutic target of human PTC.
\end{abstract}
Key Words
- macrophages
- papillary thyroid carcinoma
- CXCL16
- invasion

Endocrine-Related Cancer (2016) 23, 113-124

\section{Introduction}

A tumor microenvironment is a heterogeneous complex that includes immune cells, fibroblast, and endothelial cells as well as tumor cells (Shiao et al. 2011, Cho 2013).
Macrophages are one of the major components of the tumor microenvironment and have pivotal roles in tumor growth, metastasis, and angiogenesis (Bingle et al. 2002, 
Mantovani et al. 2002, Ohno et al. 2003, Cho 2013). Macrophages consist of a diverse population and have roles in various pathophysiologic conditions including inflammation, tissue regeneration, and cancer. Recently, it has become generally accepted that macrophages are schematically classified into two subtypes: classically activated, pro-inflammatory M1-macrophages and alternatively activated, anti-inflammatory M2-macrophages (Mantovani et al. 2002, Mosser 2003, Murray \& Wynn 2011). In tumor microenvironment, macrophages, so called tumor-associated macrophages (TAM), are commonly considered to have M2-macrophage phenotypes characterized as having a regenerative and pro-tumoral function, but not always (Bingle et al. 2002, Mantovani et al. 2002). Several epidemiological and clinical studies have shown that there are strong relationships between the high density of macrophages and the advanced stage or poor prognosis of various human cancers (Ryder et al. 2008, Colvin 2014, Tiainen et al. 2015, Yuan et al. 2014). However, the opposite results have also shown that a high density of macrophages was associated with better overall survivals in colon (Funada et al. 2003, Zhou et al. 2010) and thyroid (Cunha et al. 2012) cancers, suggesting that macrophages might have wide-raging biological actions in human cancers according to their own tumor microenvironment.

In thyroid cancers, a few epidemiologic studies have shown that high TAM densities were associated with poor pathologic subtypes, bigger tumor size, or the presence of LN metastasis (Ryder et al. 2008, Qing et al. 2012, Kim et al . 2013). Recently, several studies have been demonstrated possible molecular mechanisms of macrophage actions in PTCs, such as CXCL8 (Fang et al. 2014) or CSF1 (Ryder et al. 2013). The present study explored CXCL16 signaling as a mediator of macrophages actions on PTC cell invasiveness and demonstrated bi-directional roles of CXCL16 in macrophage-tumor interactions.

\section{Materials and methods}

\section{Reagents}

Recombinant human CXCL16, anti-human CXCL16 neutralizing antibody, and human CXCL16 Quantikine ELISA Kit were purchased from R\&D Systems (Minneapolis, MN, USA). TAPI2 (a metalloproteinase inhibitor) was purchased from Santa Cruz Biotechnology. LY294002 was purchased from Cell Signaling (Danvers, MA, USA).

\section{Cell cultures and harvesting of cell CM}

For primary culture of peripheral blood monocyte/ macrophage, peripheral blood $(35 \mathrm{ml})$ was collected in $50 \mathrm{ml}$ conical tubes containing $15 \mathrm{ml}$ of Ficoll-Paque Plus (Amersham Biosciences/GE Healthcare, Pittsburgh, PA, USA) and centrifuged at $750 \times \boldsymbol{g}$ for $20 \mathrm{~min}$ at $20^{\circ} \mathrm{C}$. After removing the upper layer, interphase cells (lymphocytes and monocytes) were collected, mixed with $0.1 \%$ BSA, and centrifuged at $350 \times \boldsymbol{g}$ for $10 \mathrm{~min}$ (once) and $160 \times \boldsymbol{g}$ for $15 \mathrm{~min}$ (twice). A total of $5 \times 10^{7}$ cells were plated on a $75 \mathrm{~cm}^{2}$ culture flask with RPMI containing 10\% FBS media. After an initial $2 \mathrm{~h}$ incubation, the supernatant with non-adherent cells was discarded and, fresh media (RPMI containing $50 \mathrm{ng} / \mathrm{ml}$ recombinant human M-CSF and $10 \%$ FBS) were applied.

The human PTC cell line, BHP10-3 cells (passage number ranged from 9 to 12) - a tumorigenic clone of the BHP10-3 cell line containing the RET/PTC rearrangement, was developed and kindly provided by Dr Soon-Hyun Ahn (Seoul National University College of Medicine, Seoul, Korea) and Dr Gary L Clayman (MD Anderson Cancer Center, Houston, TX, USA) (Ahn et al. 2008). The $B R A F^{V 600 E}$-containing human PTC cell line, KTC1 cells (passage number ranged from 6 to 9), was a kind gift from Dr J K Chung (Seoul National University College of Medicine, Seoul, Korea). Both BHP10-3 cells and KTC1 cells were authenticated by short tandem repeat (STR) profiling analysis by Korean Cell Line Bank (Seoul, Korea). Human normal thyrocyte, $\mathrm{H}$ tori cell, was obtained from Culture Collections Public Health England (Salisbury, UK). Human macrophage THP1 cells and human embryonic kidney (HEK) 293 cells were purchased from ATCC (Manassas, VA, USA) with authentication using STR assay provided by ATCC and used at passage number ranged from 2 to 4 respectively. All cells were cultured in RPMI1640 medium supplemented with $10 \%$ FBS. The cells were seeded on $100 \mathrm{~mm}$ culture dishes with $3 \times 10^{5}$ cells $/ \mathrm{ml}$ in $10 \mathrm{ml}$ of medium. After $48 \mathrm{~h}$, the media from each cell were harvested, filtered, and stored at $-70^{\circ} \mathrm{C}$. Conditioned media from BHP10-3, KTC1, H tori, THP1, or primary monocytes single cell cultures were called BHP10-3 CM, KTC1 CM, H tori CM, THP1 CM, and monocyte CM respectively. Additionally, conditioned media from BHP10-3, KTC1, and H tori cells cultured with THP1 cells or primary monocytes were called T/BHP10-3 CM, T/KTC1 $\mathrm{CM}$, and T/H tori CM, or M/BHP10-3 CM, M/KTC1 CM, and $\mathrm{M} / \mathrm{H}$ tori $\mathrm{CM}$ respectively. Protein expression properties were analyzed by cytokine array (\#ARY007, R\&D Systems) according to the manufacturer's instructions.

Published by Bioscientifica Ltd 


\section{RNA extraction and RT-PCR analysis}

Primary monocytes, THP1 cells, or BHP10-3 cells were plated and treated with indicated CM for $48 \mathrm{~h}$. The cells were washed, and the mRNAs were harvested with Trizol (Invitrogen, Carlsbad, CA, USA). RT-PCR was done with a Perkin-Elmer GeneAmp PCR System 9600 (Waltham, MA, USA). The PCR primer sets are listed in Supplementary Table S1, see section on supplementary data given at the end of this article.

\section{Cell viability and migration study}

For the cell viability study, cells were seeded onto a 96-well tissue culture plate with $100 \mu \mathrm{l}$ of medium with $1 \times 10^{4}$ cells $/ \mathrm{ml}$. After $12 \mathrm{~h}$, cells were cultured with primary monocytes, THP1, or HEK293 cells for $48 \mathrm{~h}$, and a CCK8 assay was performed (Dojindo, Kumamoto, Japan). CCK8 solution $(10 \mu \mathrm{l})$ was added to each well, and after a $6 \mathrm{~h}$ incubation, absorbance at $450 \mathrm{~nm}$ was measured with a microplate reader (Bio-Rad).

To evaluate the cell migration potential, the monolayer wound healing assay was performed as previously described (Cho et al. 2014). Briefly, for the monolayer wound healing assay, BHP10-3 cells were plated for $12 \mathrm{~h}$, and primary monocytes or THP1 cells were co-cultured with M-CSF containing RPMI-1640 medium for next $12 \mathrm{~h}$. A scratch was made through the cell monolayer with a pipette tip, and cell migrations were observed for $24 \mathrm{~h}$. For inhibition study, BHP10-3 cells were plated with or without THP1 cells, and a rake wound was generated. The THP1(-) group was treated with CXCL16 $(0.5 \mathrm{ng} / \mathrm{ml})$ with or without LY294002 $(10 \mu \mathrm{M})$, and the THP1(+) group with the neutralizing antibodies of CXCL16 $(100 \mu \mathrm{g} / \mathrm{ml})$, TAPI2 $(100 \mu \mathrm{M})$, or LY294002 $(10 \mu \mathrm{M})$. Cell migration lengths were measured at $24 \mathrm{~h}$ after rake wound generation. The length of migration was measured from the baseline of the scratch to the edge of the migration at least five different point in each well.

For transwell migration assay, $8 \mu \mathrm{m}$ pore-size polycarbonate membrane (Corning, NY, USA) was used. Membrane was pre-coated with gelatin, and the inserts were placed into a 24-well plate. The upper and lower chambers were plated with primary monocytes or THP1 cells and BHP10-3 or KTC1 cells respectively. After $6 \mathrm{~h}$, non-migrating cells were removed from the surface of the upper membrane with a cotton-tipped applicator and the inserts were stained with $1 \%$ crystal violet solutions.

\section{D invasion assay}

3D invasion assay was performed on BHP10-3 or KTC1 cells, using Cultrex 3D Spheroid Cell Invasion Assay (Trevigen, Inc., Gaithersburg, MD, USA). Briefly, $3 \times 10^{3}$ cells were dispensed in $50 \mu \mathrm{l}$ of Spheroid Formation ECM per well and incubate at $37^{\circ} \mathrm{C}$ for $72 \mathrm{~h}$. Working on ice, $50 \mu \mathrm{l}$ of Invasion Matrix were added to each well and the plate was incubated at $37^{\circ} \mathrm{C}$ for $1 \mathrm{~h}$. After gel formation, $100 \mu$ of indicated $\mathrm{CMs}$ were added to each cell: $\mathrm{M} / \mathrm{H}$ tori or M/BHP10-3 CMs to BHP10-3 cells, and M/H tori or M/KTC1 CMs for KTC1 cells. After 4 days of incubation at $37^{\circ} \mathrm{C}$, invasions were observed under microscope using the $4 \mathrm{X}$ objective, and spheroid images were analyzed by ImageJ (http://imagej.nih.gov/ij/index.html).

\section{Immunofluorescence staining}

Cells were plated on glass coverslips and treated with M/BHP10-3 or M/H tori CMs for $48 \mathrm{~h}$. Cells were fixed with $4 \%$ paraformaldehyde after washing and applied with $0.05 \%$ Triton X-100 for permeabilization. After blocking with $10 \%$ BSA solution, cells were incubated with rabbit anti-CXCL16 antibody (dilution ratio 1:100, cat \#ab101404; Abcam) for 12 h. Alexa Fluor 594 goat antirabbit antibody (dilution ratio 1:500; Molecular Probes, Grand Island, NY, USA) was used as secondary antibody. Cell nuclei were stained with nuclear binding 4',6diamidino-2phenylindole (DAPI) dye. Fluorescence analyses were performed with a spinning disk confocal microscope (Carl Zeiss, Jena, Germany) using the target activation assay algorithm as a part of the Cellomics Arrayscan VTI platform (Cellomics, Pittsburg, PA, USA).

\section{Western blot analysis}

BHP10-3 cells were treated with CXCL16 $(0.5 \mathrm{ng} / \mathrm{ml})$ or co-cultured with THP1 cells following anti-CXCL16 $(100 \mu \mathrm{g} / \mathrm{ml})$ or LY294002 $(10 \mu \mathrm{M})$-treatment. After $48 \mathrm{~h}$, cell lysates were harvested. Anti-mTOR (dilution ratio 1:500, \#2972; Cell Signaling), anti-pAkt (dilution ratio 1:2000, \#9102; Cell Signaling), anti-Akt (dilution ratio 1:2000, \#4370; Cell Signaling), and anti-GAPDH antibodies were used.

\section{Study subjects and construction of tissue microarrays}

Thyroid tissue microarrays were constructed as previously described (Cho et al. 2014). Briefly, human thyroid tissues were obtained from January 1993 to December 2003

Published by Bioscientifica Ltd. 
surgical pathology files from the Departments of Pathology at Seoul National University Boramae Medical Center and Seoul National University Hospital. Hematoxylin and eosin (H\&E) stained thyroid tissues were examined by two different pathologists with slides, and a single, appropriate paraffin block (donor block) was selected for each case. Core thyroid tissue biopsies $(2 \mathrm{~mm}$ in diameter) were taken from individual paraffinembedded thyroid tissue donor blocks. The final four tissue arrays consisted of samples from patients with various thyroid tissues including 136 PTC samples. All experimental procedures were done in accordance with the guidelines proposed in The Declaration of Helsinki (http://www.wma.net) involving humans. Moreover, all experiments were approved by the institutional review boards of Seoul National University Hospital (1107-060369) and Seoul National University Boramae Medical Center (06-2010-176).

\section{Immunohistochemical staining}

Immunohistochemical analysis for CD163 (Cell Signaling; diluted 1:1000), CXCR6 (R\&D system; diluted 1:250), and CXCL16 (Abcam; diluted 1:1000) were done on formalinfixed, paraffin-embedded tissue sections with the BenchMark XT automated immunohistochemistry slide staining system (Ventana; Tucson, AZ, USA), according to the manufacturer's instructions. To analyze immunoreactivities, the core areas of tumors were divided into quarters, and five areas were randomly chosen from each quarter and central area. Under $400 \times$ magnification, $\mathrm{CD} 163^{+}$or $\mathrm{CXCR}^{+}$cells were counted by two different medical doctors including one pathologist and expressed as the number of cells per $10^{3} \mu \mathrm{m}^{2}$ section area. The immunohistostaining intensity of CXCL16 was scored from 0 to 3 , at a $400 \times$ magnification, and the percentage of positive cells were calculated as: $0,<5 \% ; 1,5-25 \%$; $2,25-50 \% ; 3,50-70 \% ; 4$, more than $75 \%$, at a $100 \times$ magnification. The final score, $0-3$, was defined as the sum of the intensity and percentage.

\section{Statistical analysis}

For analysis of continuous variables, means and standard errors were calculated. After the distribution normality was determined with the Kolmogorov-Smirnov test, the Kruskal-Wallis test with the Mann-Whitney $\mathrm{U}$ test or a one-way ANOVA with post-hoc analysis was applied to the data. For analysis of the categorical variables, frequencies and percentages were determined.
Proportions were compared with the $\chi^{2}$ test or Fisher's exact test. Statistical analysis was done with SPSS version 19.0. All $P$ values were two-sided, and a $P<0.05$ was considered statistically significant.

\section{Results}

\section{Macrophage supported PTC cell invasions}

To investigate the effects of macrophages on PTC cells, cell viability and migration studies were performed in PTC and macrophage co-culture system. First, two different PTC cells, BHP10-3, and KTC1, were cultured with primary monocytes or THP1 cells, and cell viability were evaluated. CCK8 assay shows that there was no significant difference in cell viabilities (data not shown).

Next, cell migration assays were performed using wound healing assay and transwell system. Wound healing assay showed that co-cultures with primary monocytes (Fig. 1A) or THP1 cells (Fig. 1B) had a significant enhancement in cell migrations at $24 \mathrm{~h}$ in the BHP10-3 cells. Transwell migration assay also demonstrated 2.8- and 1.7-fold increases of tumor cell migrations in co-cultures of primary monocytes and THP1 cells respectively (Fig. 1C). KTC1 cells co-cultured with primary monocytes showed similar results comparable with BHP10-3 cells (Fig. 1D). Furthermore, 3D invasion assay was performed using CMs from co-cultures of monocyte and PTC cell lines. CM form co-cultures of monocyte and human normal thyrocyte, $\mathrm{H}$ tori cell was used as control. As shown in Fig. 1E and F, M/BHP10-3 CM increased BHP10-3 cell invasion compared with $\mathrm{M} / \mathrm{H}$ tori $\mathrm{CM}$ (Fig. 1E), while M/KTC1 CM showed no effects on KTC1 cell invasion (Fig. 1F).

Subsequently, the potential mediators of the macrophage effects on tumor cell migrations were explored. CMs from $\mathrm{H}$ tori, BHP10-3, KTC1 cultured with or without primary monocytes or THP1 cells were analyzed with cytokine array analysis. A total of 55 proteins related to tissue growth and angiogenesis were screened, and CXCL16 expression was up-regulated in both T/BHP10-3 CM, M/BHP10-3 CM, T/KTC1 CM, or M/KTC1 CM compared with the $\mathrm{T} / \mathrm{H}$ tori $\mathrm{CM}, \mathrm{M} / \mathrm{H}$ tori or to the $\mathrm{CMs}$ from single cell cultures (primary monocyte, $\mathrm{H}$ tori, BHP10-3, THP1, or KTC1). ELISA assay confirmed that CXCL16 levels were only present in CMs from T/BHP10-3 $(230 \pm 24 \mathrm{pg} / \mathrm{ml}), \mathrm{M} / \mathrm{BHP} 10-3(325 \pm 32 \mathrm{pg} / \mathrm{ml}), \mathrm{T} / \mathrm{KTC} 1$ $(32 \pm 6 \mathrm{pg} / \mathrm{ml})$, and $\mathrm{M} / \mathrm{KTC} 1(109 \pm 12 \mathrm{pg} / \mathrm{ml})$ (Fig. 2A).

To explore the cellular origin of CXCL16 production, immunofluorescence staining with anti-CXCL16 antibody was performed. Treatment with M/BHP10-3 CM increased

Published by Bioscientifica Ltd. 
A

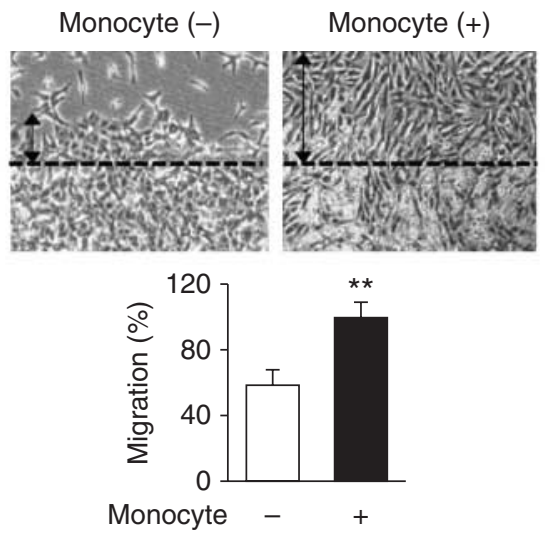

C

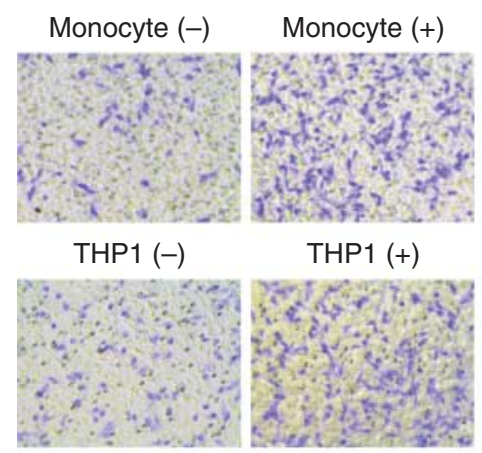

E

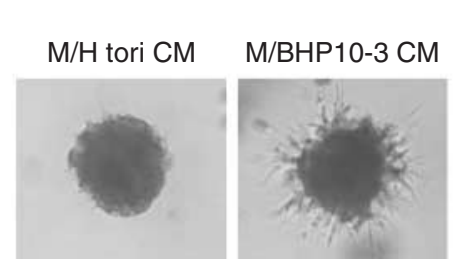

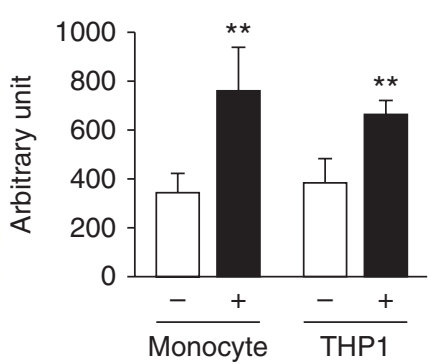

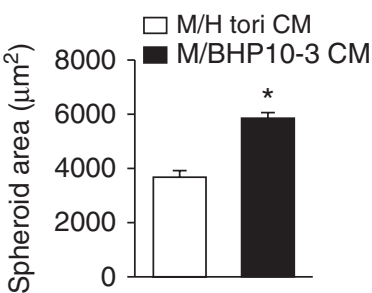

B
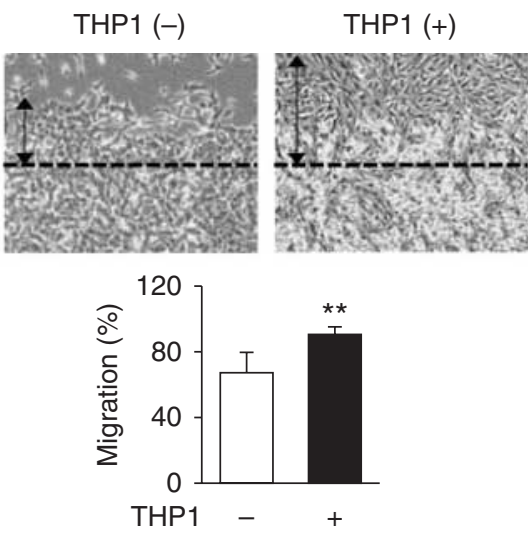

D

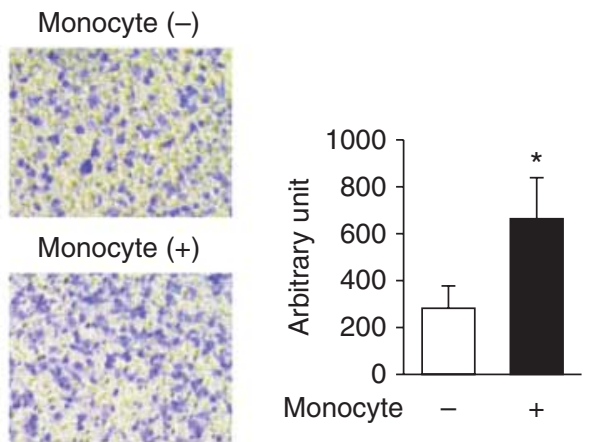

$\mathrm{F}$

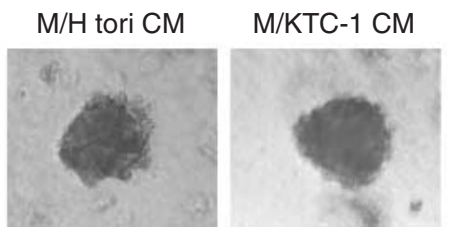

\section{Figure 1}

Macrophage supported PTC cell migration. (A and B) BHP10-3 cells were co-cultured with (A) primary monocytes or (B) THP1 cells and the wound healing assay was done. Cell migration lengths were measured at $24 \mathrm{~h}$ after rake wound generation. $P<0.01$. ( $C$ and $D$ ) Transwell migration assays were performed. (C) Primary monocytes or THP1 cells were cultured in lower chamber and upper chambers plated with BHP10-3 cells were inserted. (D) Primary monocytes were cultured in lower chamber and upper chambers were plated with KTC1 cells.

the CXCL16 expressions in the primary monocytes but not in the BHP10-3 cells, compared with $\mathrm{M} / \mathrm{H}$ tori CM-treatment (Fig. 2B). Furthermore, the mRNA expression of CXCL16 and CXCR6, a membrane receptor of CXCL16, were analyzed in primary monocyte and BHP10-3 cells. M/BHP10-3 CM treatment significantly up-regulated CXCR6 expressions in both primary monocytes and BHP10-3 cells by threefold respectively (Fig. 2C). BHP10-3 CM and M/BHP10-3 CM up-regulated CXCL16 by 2 - and 6 -fold in the primary monocytes, while M/BHP10-3 CM alone marginally up-regulated CXCL16
After $6 \mathrm{~h}$, migrated cancer cells were stained with crystal violet and calculated using color deconvolution plugin in Image J program. ( $E$ and F) 3D invasion assay was performed. (E) BHP10-3 or (F) KTC1 cells were dropped into 96 well and spheroid formation was observed for $48 \mathrm{~h}$. Area of spheroids were measured by ImageJ. $P<0.05$ and $P<0.01$. Data are shown as the mean \pm s.E.M. of triplicates from two independent experiments. A full colour version of this figure is available at http://dx.doi.org/10.1530/ERC-15-0190.

by 1.4-fold in the BHP10-3 cells (Fig. 2D). Collectively, the major production of CXCL16 might come from monocyte/macrophages in PTC microenvironments, and both the monocyte/macrophage and PTC cells might respond to CXCL16 through CXCR6.

\section{CXCL16 mediated macrophage effects on PTC cell migrations}

Next, we checked the effects of CXCL16 in the interactions between PTC cells and monocytes. Treatment of

Published by Bioscientifica Ltd. 


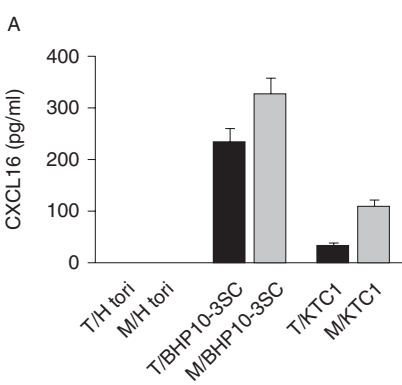

B

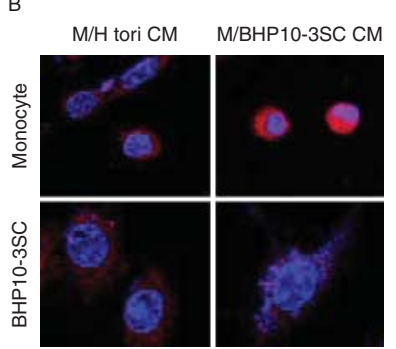

C

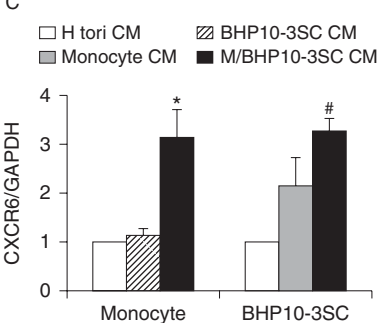

D

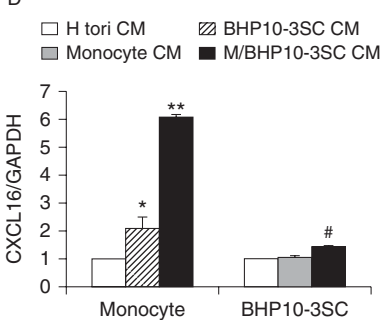

Figure 2

Enhanced CXCL16 expressions in PTC tumor microenvironment. (A) CXCL16 levels were measured in the CMs from $\mathrm{H}$ tori, BHP10-3, and KTC1 co-cultured with THP1 (T/H tori, T/BHP10-3, or T/KTC1) or monocytes (M/H tori, M/BHP10-3, or M/KTC1). (B) Monocytes or BHP10-3 cells were treated with M/BHP10-3 CM or M/H tori $\mathrm{CM}$, and $\mathrm{CXCL} 16$ expressions were verified

rhCXCL16 enhanced the cell migration potential comparable with that of the co-culture with the THP1 cell group, and blocking CXCL16 with neutralizing antibody reduced the THP1 mediated increases in cell migration potential (Fig. 3A). Treatment with TAPI2, a metalloproteinase inhibitor, which could inhibit the shedding of CXCL16, also attenuated the THP1 mediated increases in cell migration potential (Fig. 3A). Western blot analyses showed that treatment with rhCXCL16 increased Akt phosphorylation in BHP10-3 cells and LY294002, a selective inhibitor of PI3K/Akt, attenuated it (Fig. 3B). Consistently, co-culture with THP1 cells also showed increased Akt phosphorylation compared with the BHP10-3 cell single culture and treatment of CXCL16 neutralizing antibody or LY294002 also reduced it (Fig. 3B).

Finally, blocking Akt signaling with LY294002 inhibited BHP10-3 cell migration potentials not only in treatment of rhCXCL-16 (Fig. 3C, upper images), but also in co-culture with THP1 cells (Fig. 3C, lower images).

\section{CXCL16 mediated macrophage polarization in PTC tumor microenvironments}

To investigate the macrophage phenotypes in the PTC tumor microenvironment, primary monocytes were treated with $\mathrm{H}$ tori CM, BHP10-3 CM, or KTC1 CM for $48 \mathrm{~h}$, and the mRNA expressions of M1/M2-macrophage related genes were analyzed. Interestingly, M2-macrophage related genes, such as CD163, IL10, and CD206 were significantly up-regulated with BHP10-3 CM or KTC1 CM treatment than with $\mathrm{H}$ tori $\mathrm{CM}$ treatment (White columns in Fig. 4A). Meanwhile, M1-macrophage related genes showed different expressions: IL1 $\beta$ and iNOS expressions by immunofluorescence staining. ( $C$ and $D$ ) Indicated CMs were treated with monocytes or BHP10-3 cells for $48 \mathrm{~h}$, and mRNA expressions of (C) CXCR6 or (D) CXCL16 were analyzed by quantitative RT-PCR. $P<0.05$ and $P<0.01$ vs $\mathrm{H}$ tori $\mathrm{CM}$-treated monocytes, $P<0.05$ vs $\mathrm{H}$ tori $\mathrm{CM}$-treated BHP10-3 cells.

were not changed with BHP10-3 CM or KTC1 CM treatment (Fig. 4B). Similar results were confirmed with THP1, a human macrophage cell-line (Supplementary Fig. 1, see section on supplementary data given at the end of this article), suggesting that monocyte/macrophages might have an M2-macrophage phenotype rather than an M1-macrophage phenotype in tumor microenvironments. More interestingly, blocking CXCL16 signaling inhibited PTC CM-mediated up-regulations of CD163, IL10, and CD206 in primary monocytes (black columns in Fig. 4A). Treatment with CXCL16, per se, also up-regulated M2-macrophage related genes including CD163 and IL10, and did not affect M1-macrophage related gene expressions such as IL1 $\beta$ and iNOS (Fig. 4C), which was similar to that of CM-treatment in Fig. 4A (white columns). Collectively, activated CXCL16 signaling supports macrophage polarization in tumor microenvironments.

\section{CXCR6/CXCL16 expressions in human PTC tissues}

Finally, CXCR6 and CXCL16 expressions were investigated in human PTC tissues. Among 136 PTC tissues, in the tissue microarray, 15 (10\%) and 43 (30\%) of them showed cancer-dominant (Fig. 5A) and stromal-dominant expressions of CXCR6 (Fig. 5B) respectively. Ten (7\%) of them showed cancer and stromal co-expressions of CXCR6 (Fig. 5C). CXCL16 was also expressed in either cancer or stromal sites: cancer dominant, $n=24(18 \%$, Fig. 5D); stromal-dominant, $n=44$ (32\%, Fig. 5E); and cancer and stromal co-expressions, $n=20$ (15\%, Fig. $5 \mathrm{~F}$ ) respectively. To evaluate the association between CXCR6 and CXCL16 expressions, CXCR6 expressions were divided into two groups according to the median value of the number of CXCR6 ${ }^{+}$cells $\left(36 / 10^{3} \mu \mathrm{m}^{2}\right)$, low-density

Published by Bioscientifica Ltd. 
A

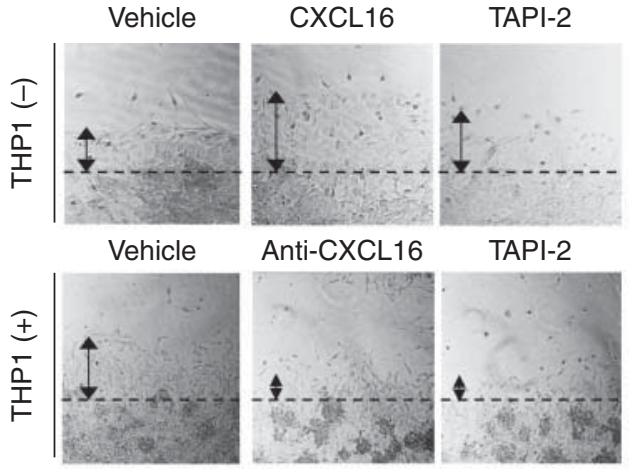

B

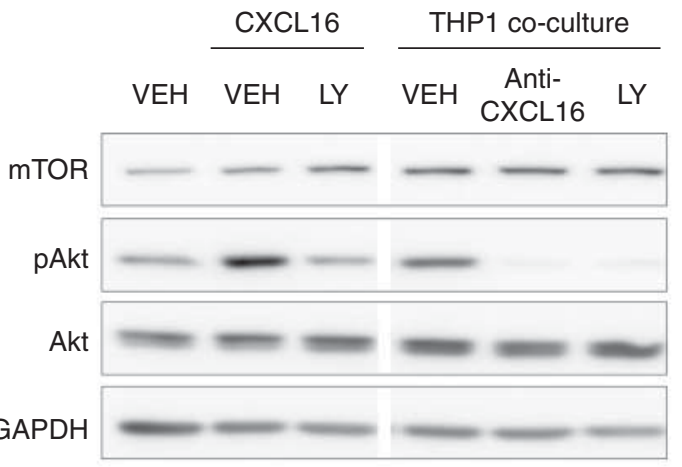

C

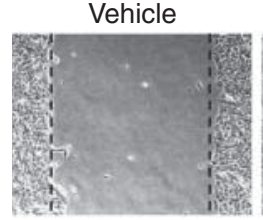

THP1

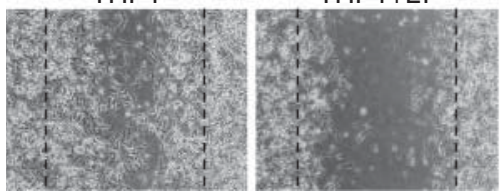

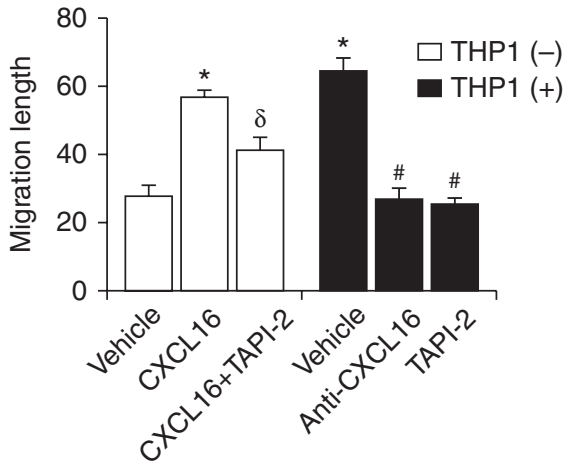

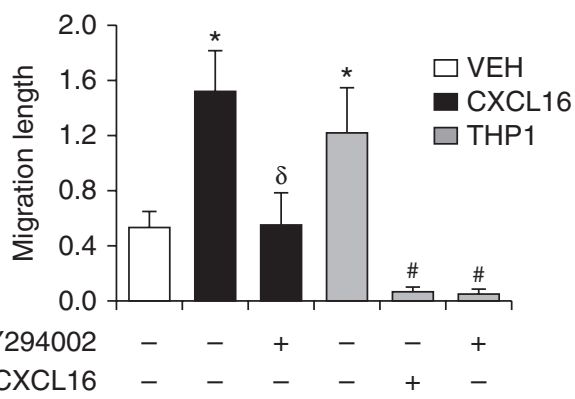

Anti-CXCL16 - $\quad-\quad-+-$

\section{Figure 3}

CXCL16 mediated macrophage effects on PTC cell migration. (A) BHP10-3 cells were plated with or without THP1 cells, and a rake wound was generated. The THP1 $(-)$ group was treated with CXCL16 $(0.5 \mathrm{ng} / \mathrm{ml})$ and the THP1 $(+)$ group with the neutralizing antibodies of CXCL16 $(100 \mu \mathrm{g} / \mathrm{ml})$ or TAPI2 $(100 \mu \mathrm{M})$. Cell migration lengths were measured at $24 \mathrm{~h}$ after rake wound generation. $P<0.05$ vs vehicle of THP1 $(-) ;{ }^{\delta} P<0.05$ vs CXCL16 of THP1 $(-) ; P<0.05$ vs vehicle of THP1(+). (B) BHP10-3 cells were treated with CXCL16 $(0.5 \mathrm{ng} / \mathrm{ml})$ or co-cultured with THP1 cells. LY294002 $(10 \mu \mathrm{M})$ was treated to both CXCL16 treated group or THP1- co-cultured group.

$\left(15.8 \pm 11.8 / 10^{3} \mu \mathrm{m}^{2}, \quad n=68\right)$ and high-density (58.8 \pm $\left.14.0 / 10^{3} \mu \mathrm{m}^{2}, n=68\right)$, and the association with CXCL16 expressions, graded by four groups, were analyzed by Chi square test. Interestingly, high density of CXCR6 group showed higher grades of CXCL16 expressions only
Neutralizing antibodies of CXCL16 $(100 \mu \mathrm{g} / \mathrm{ml})$ was added to THP1 co-cultured group. Western blot analyses were performed with the antipAkt, Akt, and GAPDH antibodies. $P<0.05$ vs VEH (1st column); ${ }^{\delta} P<0.05$ vs CXCL16/VEH (2nd column); $P<0.05$ vs THP1 co-culture/VEH (C) BHP10-3 cells were plated following treatment of CXCL16 $(0.5 \mathrm{ng} / \mathrm{ml})$ with or without LY294002 $(10 \mu \mathrm{M})$ (upper images). BHP10-3 cells were co-cultured with THP1 cells and LY294002 $(10 \mu \mathrm{M})$ were treated (lower images). Cell migration lengths were measured at $24 \mathrm{~h}$ after rake wound generation. $P<0.01$ vs VEH; ${ }^{\delta} P<0.05$ vs LY $(-)$ in CXCL16; $P<0.05$ vs $L Y(-)$ in THP1. VEH, vehicle.

in cancer-dominant or cancer + stromal expression groups of CXCR6, but not in stromal-dominant group (Table 1).

Moreover, a number of CXCR6 ${ }^{+}$cells showed positive correlations with that of $\mathrm{CD} 163^{+}$cells $\left(\gamma^{2}=0.280\right.$, $P<0.001$, Fig. 5G). Especially, the mean number of 


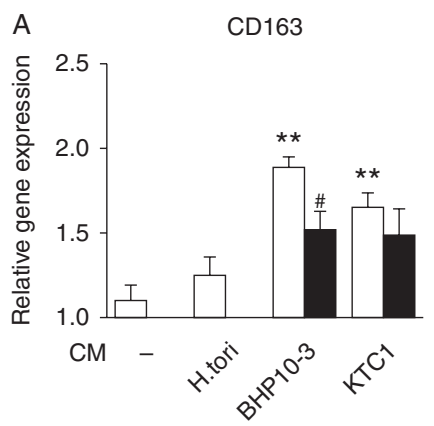

B

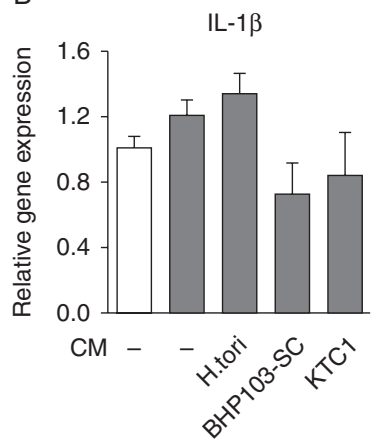

$\mathrm{IL}-10$

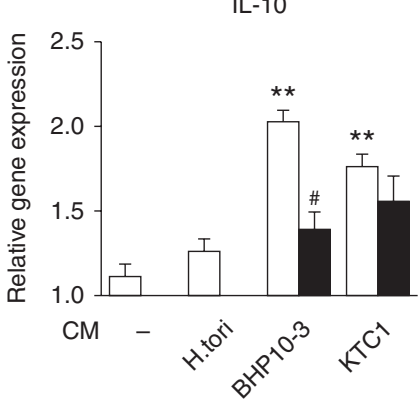

C

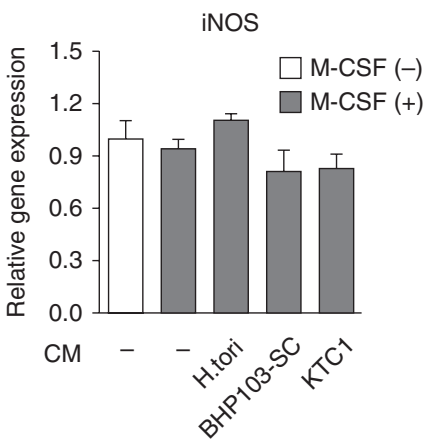

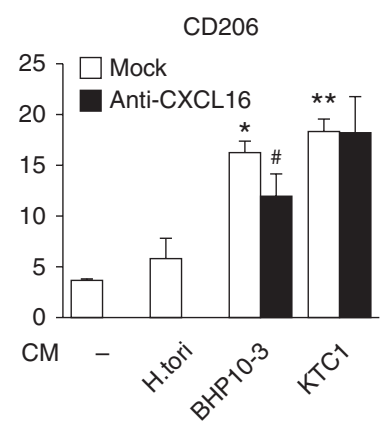

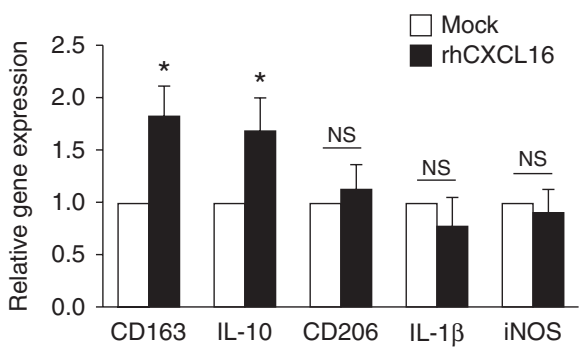

Figure 4

CXCL16 mediated macrophage polarization in PTC tumor microenvironments. (A) Primary monocytes were treated with $50 \% \mathrm{CMs}$ from $\mathrm{H}$ tori, BHP10-3, and KTC1. CMs of BHP10-3 and KTC1 groups were treated with anti-CXCL16 antibodies $(100 \mu \mathrm{g} / \mathrm{ml})$ simultaneously. mRNA expressions of $C D 163, I L 10$, and CD206 were analyzed. $P<0.05$ and $P<0.01$ vs $\mathrm{H}$ tori $C M$ group (2nd column in each graph). $P<0.05$ vs mock in each group.

(B) Primary monocytes were treated with $50 \% \mathrm{CMs}$ from $\mathrm{H}$ tori, BHP10-3, and KTC1. mRNA expressions of IL1 $\beta$ and iNOS were analyzed. (C) Monocytes were treated with CXCL16 $(0.5 \mathrm{ng} / \mathrm{ml})$, and mRNA expressions of indicated genes were analyzed. $P<0.05$ vs mock; NS, not significant. All mRNA expressions were analyzed by quantitative real-time RT-PCR and data are shown as the mean \pm s.E.M. of triplicates from two independent experiments.
$\mathrm{CD}_{163}{ }^{+}$cells was significantly higher in cancer and stromal co-expression group than others (Fig. $5 \mathrm{H}$ ).

Next, the clinical characteristics were compared between two CXCR6 groups, low and high-density. Their mean numbers of $\mathrm{CD}_{163}{ }^{+}$cells were higher in highdensity than low-density group $(50.9 \pm 25.3$ vs $25.8 \pm$ $\left.16.9 / 10^{3} \mu \mathrm{m}^{2}, P<0.001\right)$. Age at diagnosis, sex, and extrathyroidal invasion showed no differences between the groups, and tumor size showed a tendency to be larger in the high than in the low density group but without any statistical significance $(2.3 \pm 1.0$ vs $2.7 \pm 1.7 \mathrm{~cm}$, $P=0.089$, Table 2). The frequency of $B R A F^{V 600 E}$, a driver mutation of thyroid cancer and proposed to be associated with a poor prognosis (Ahn et al. 2014), showed no difference between the groups. However, the LN metastasis rates were higher in the high-density than in the low-density group ( $81 \%$ vs $56 \%, P<0.001$, Table 2 ). During a median 6.5 (range, 1.0-16.0) year follow-up period, disease-free survival rates showed no significant differences (data not shown). The 10 year disease-free survival rates were $79 \%$ in the low-density group and $71 \%$ in the high-density group ( $P=0.770$ from Log-rank test).

\section{Discussion}

In this study, we first identified that CXCL16 plays a pivotal role in the interaction between thyroid cancer and monocyte/macrophages. CXCL16 was one of the abundant cytokines in macrophage/PTC co-cultured CM, which seemed to mainly originate from PTC-stimulated macrophages. Blocking CXCL16 signaling using neutralizing antibody or Akt inhibitor attenuated macrophagedependent PTC cell migrations, suggesting that CXCL16 signaling partly mediated macrophage actions on PTC cell migrations. Moreover, CXCL16 also affected macrophages M2 polarization in PTC microenvironments. Finally, the expression of CXCR6 and CXCL16 showed a positive correlation with $\mathrm{CD}_{163^{+}}$macrophages in human PTC

Published by Bioscientifica Ltd 


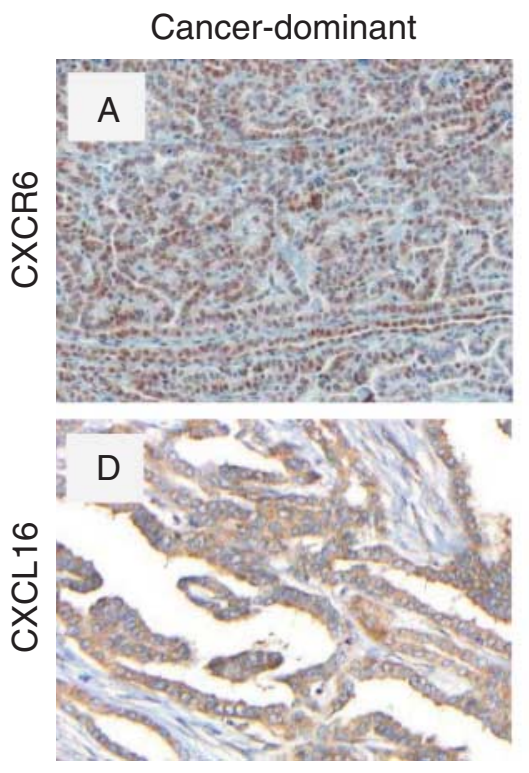

G

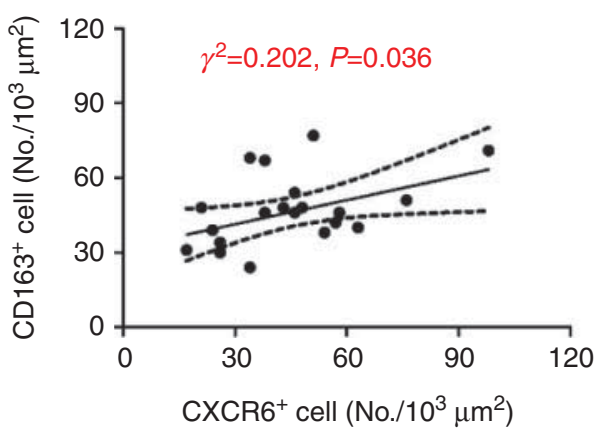

Stromal-dominant
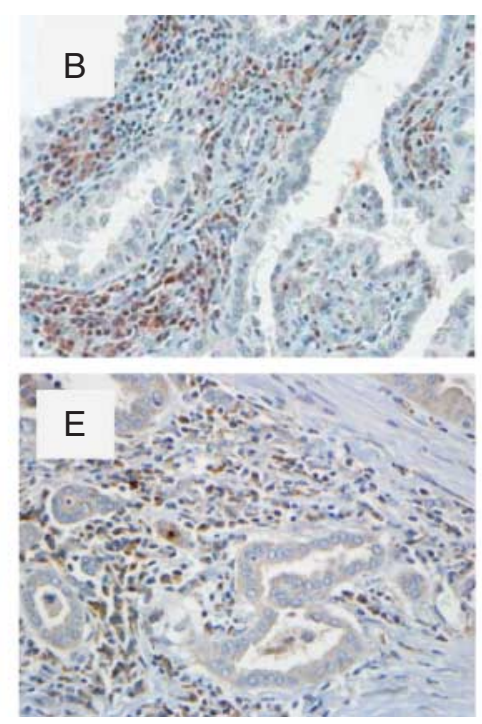

Cancer+stromal
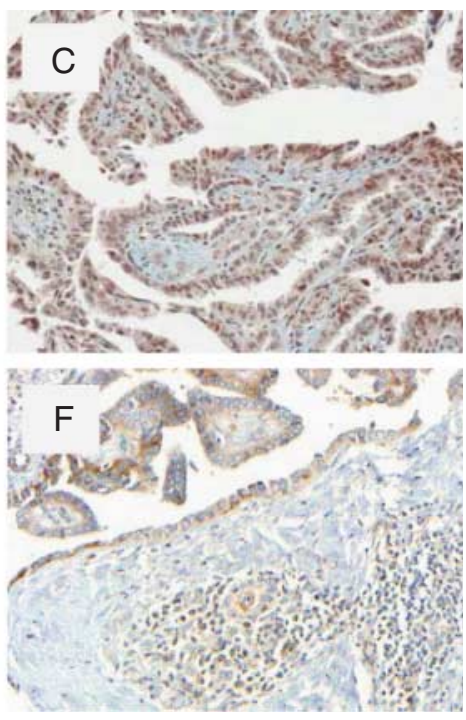

$\mathrm{H}$

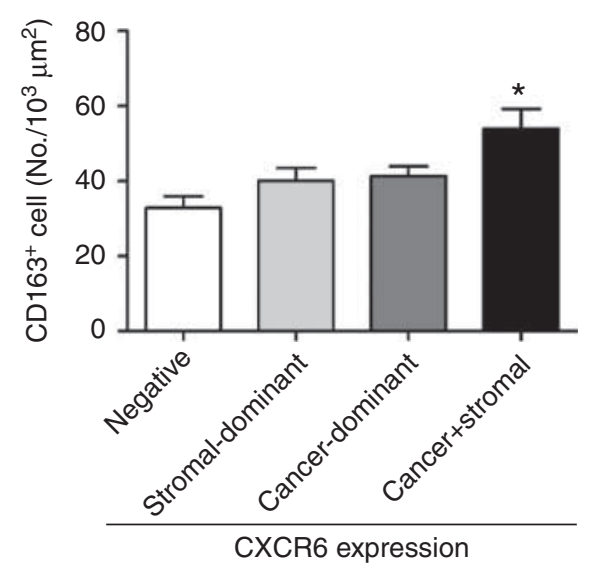

Figure 5

Expression of CXCR6 or CXCL16 in PTC tissues. Immunohistochemical staining was done in the PTC tissue microarray with anti-CXCR6 or antiCXCL16 antibodies $(n=143)$. Representative images of (A) cancer dominant, (B) stromal dominant, and (C) cancer and stromal co-expression of CXCR6, and (D) cancer dominant, (E) stromal dominant, and (F) cancer and

tissues, and associated with LN metastasis. Collectively, CXCL16 signaling might play a role in macrophagemediated PTC tumor invasiveness.

The role of macrophages in thyroid cancer is complex. Ryder et al. (2008) first demonstrated that high density of macrophages was associated with poor clinical outcome in advanced thyroid cancer, while following data have shown conflicting results (Ryder et al. 2008, Cunha et al. 2012, Qing et al. 2012, Kim et al. 2013, Fang et al. 2014). Meanwhile, recent experimental studies have been more focused on the pro-tumorigenic roles of macrophages.

stromal co-expression of CXCL16. (G) Correlations of the number of $\mathrm{CD}_{163}{ }^{+}$cells and $\mathrm{CXCR6}{ }^{+}$cells in PTC tissues. (H) Mean $\mathrm{CD} 163^{+}$cells of each CXCR6 expression group. $P<0.05$ vs stromal dominant ( 2 nd column) or cancer dominant (3rd column).

An animal study with a BRAF-induced PTC model showed that TAMs densely infiltrated into the PTC tumors and had pro-tumorigenic roles through the CSF1 receptor or CCR2 (Ryder et al. 2013). Another study showed that in vitro treatment with macrophages CM enhanced the PTC cell migration potential through CXCL8 signaling, and treatment with CXCL8 promoted PTC metastasis in a mouse model (Fang et al. 2014). In the present study, we also demonstrated that macrophages supported tumor cell migration through CXCL16 signaling. Collectively, macrophage might have a role in tumor progression not

Published by Bioscientifica Ltd 
Table 1 Associations between CXCR6 and CXCL16 expressions in human PTCs

\begin{tabular}{|c|c|c|c|c|c|c|}
\hline \multirow[b]{2}{*}{ CXCR6 } & \multicolumn{2}{|c|}{$\begin{array}{c}\text { Stromal } \\
\text { dominant }(n=42)\end{array}$} & \multirow[b]{2}{*}{$P$ value } & \multicolumn{2}{|c|}{$\begin{array}{c}\text { Cancer dominant } \\
\text { and cancer }+ \\
\text { stromal }(n=25)\end{array}$} & \multirow[b]{2}{*}{$P$ value } \\
\hline & Low & High & & Low & High & \\
\hline \multicolumn{7}{|l|}{ CXCL16 } \\
\hline 0 & 2 & 7 & 0.279 & 1 & 4 & 0.017 \\
\hline 1 & 4 & 7 & & 5 & 4 & \\
\hline 2 & 3 & 14 & & 0 & 5 & \\
\hline 3 & 0 & 5 & & 0 & 6 & \\
\hline
\end{tabular}

only in poorly differentiated thyroid cancers but also in conventional PTCs, and macrophage-related signaling pathways could be potential therapeutic targets in PTC treatment.

In this study, we derived CXCL16 as a novel mediator of macrophage actions, especially for the supportive effects on cell migration potential. CXCL16 is a ligand for CXCR6, a member of the seven transmembrane $G$ protein-coupled receptor family, and signals through the Akt pathway (Meijer et al. 2008). Independent of macrophages, the CXCL16-CXCR6 complex has been shown to promote cancer proliferation or metastasis in prostate (Lu et al. 2008, Jung et al. 2013), renal (Gutwein et al. 2009), and pancreatic (Wente et al. 2008) cancer. One of the unidentified issues in the role of CXCL16 signaling in cancers is on the functional divergence of two different types of CXCL16 proteins: soluble and trans-membrane forms. Meijer et al. (2008) showed that the two types of CXCL16 had different roles in cell proliferation and metastasis, and a certain model suggested that the soluble CXCL16 induces cancer cell proliferation and metastasis (Deng et al. 2010), while the trans-membrane CXCL16 suppressed it. However, it is still unclear and needs to be redefined according to specific tissues. In this study, we focused on the soluble CXCL16, as a secretory factor of TAMs. Treatment with rhCXCL16 enhanced the migration potential of the PTC cells, and TAM-mediated PTC cell migration was inhibited not only by the antiCXCL16 neutralizing antibody but also by a disintegrin and metalloprotease (ADAM) 17 inhibitor (TAPI2). Because ADMA17 is one of the cleavage proteins of CXCL16, converting trans-membrane CXCL16 into soluble form (Abel et al. 2004, Gough et al. 2004, Ludwig et al. 2005, Schramme et al. 2008), it is clear that these effects were medicated by the soluble CXCL16 rather than the trans-membrane form. To our knowledge, this is the first report that shows soluble CXCL16 as a downstream mediator of macrophage actions in human cancer. Because CXCL16 has been reported to be expressed not only in macrophages but also in various human cancers including thyroid, it is not easy to determine the origin of CXCL16 in a tumor microenvironment. In this study, treatment with M/BHP10-3 CM strongly up-regulated CXCL16 gene expression in macrophages, but not in PTC cells, suggesting that macrophages could be the major source of CXCL16 production. Different from CXCL16 gene expressions, mRNA expressions of CXCR6 were similarly increased in response to the M/BHP10-3 CM in both monocytes and BHP10-3SC cells. These might be reflected the dual actions of CXCL16 in tumor microenvironment, enhancing tumor cell migration and effecting macrophage polarization. Although we could not dissect out the cellular origin of Akt or mTOR proteins in western blot analysis of co-cultured cells, rhCXCL16 treatment into PTC cell showed similar changes of them, and Akt inhibitor attenuated macrophagedependent cell migrations, suggesting that these macrophage actions in PTC cells were mediated via CXCL16/Akt signaling. Moreover, because CXCL16 reacted to BHP10-3 and M/BHP10-3 CM but not to THP1 CM, and the response was greater with M/BHP10-3 co-cultured CM than with BHP10-3 CM, we can presume that the cell-cell interactions of the macrophages and cancer cells could be one of the pivotal factors conditioning the macrophage-related tumor microenvironment with CXCL16. However, we were not able to show the trigger mechanism of CXCL16 secretion in this study. Further studies are needed.

Different to CXCL16, CXCR6 expression was increased in macrophages, BHP10-3 cells, and endothelial cells. Furthermore, immunohistochemical staining of the tissue microarray of PTCs showed that CXCR6 was expressed in both cancer cells and stroma including

Table 2 Clinical characteristics of PTC patients according to the tumor associated macrophage density

\begin{tabular}{|c|c|c|c|}
\hline CXCR6 & $\begin{array}{c}\text { Low } \\
\text { density } \\
(n=68)\end{array}$ & $\begin{array}{c}\text { High } \\
\text { density } \\
(n=68)\end{array}$ & $\begin{array}{c}P \\
\text { value }\end{array}$ \\
\hline Number of $\mathrm{CXCR}^{+}$cells & $15.8 \pm 11.8$ & $58.8 \pm 14.0$ & $<0.001$ \\
\hline Female sex $(n)(\%)$ & $54(79)$ & $57(84)$ & 0.659 \\
\hline Age of diagnosis (years) & $49.4 \pm 16.7$ & $50.6 \pm 15.2$ & 0.665 \\
\hline Tumor size $(\mathrm{cm})$ & $2.3 \pm 1.0$ & $2.7 \pm 1.7$ & 0.089 \\
\hline LN metastasis $(n)(\%)$ & $38(56)$ & $55(81)$ & 0.003 \\
\hline Extrathyroidal invasion $(n)(\%)$ & $10(19)$ & $18(27)$ & 0.385 \\
\hline$B R A F^{V 600 E}(n)(\%)$ & $38(68)$ & $37(63)$ & 0.696 \\
\hline Distant metastasis $(n)(\%)$ & $3(5)$ & $2(3)$ & 0.773 \\
\hline Recurrence $(n)(\%)$ & $3(5)$ & $3(5)$ & 0.882 \\
\hline Number of $\mathrm{CD} 163^{+}$cells & $25.8 \pm 16.9$ & $50.9 \pm 25.3$ & $<0.001$ \\
\hline
\end{tabular}

Published by Bioscientifica Ltd. 
macrophages and endothelial cells, suggesting that CXCL16 could have various actions in macrophage-rich microenvironments. Indeed, CXCL16/CXCR signaling mediated macrophage polarization into M2 characteristics, enhanced the PTC cell migration potential, and reinforced angiogenesis.

One question not answered is how monocytes/ macrophages are recruited into tumor microenvironments. Because CXCL16 has been reported to facilitate recruitment of mesenchymal stem cells or embryonic-like cells into prostate cancers (Jung et al. 2013), it is reasonable to hypothesize that CXCL16 signaling has a role in the recruitment of monocyte/macrophage. Further studies are needed to validate this hypothesis.

In this study, CXCL16 signaling partly mediated macrophage actions on PTC tumor cell invasion and also changed the macrophage phenotypes into M2macrophages in PTC tumor microenvironment. These data support the therapeutic potential of targeting macrophages or their downstream mediators for human PTC treatments.

\section{Supplementary data}

This is linked to the online version of the paper at http://dx.doi.org/10.1530/ ERC-15-0196.

\section{Declaration of interest}

The authors declare that there is no conflict of interest that could be perceived as prejudicing the impartiality of the research reported.

\section{Funding}

This research was supported by a grant from the Next-Generation BioGreen 21 Program (No. PJ00954003), Rural Development Administration, Republic of Korea, and a grant of the Korea Health Technology R\&D Project through the Korea Health Industry Development Institute (KHIDI), funded by the Ministry of Health \& Welfare, Republic of Korea (HI14C1277).

\section{Author contribution statement}

S W Cho and Y J Park: study design, acquisition or analysis and interpretation of data, and drafting the article; $\mathrm{Y} \mathrm{A} \mathrm{Kim,} \mathrm{H}$ J Sun, Y A Kim, and BHO: acquisition or analysis and interpretation of data; $\mathrm{K} \mathrm{H} \mathrm{Yi} \mathrm{and} \mathrm{D} \mathrm{J} \mathrm{Park:} \mathrm{study} \mathrm{design} \mathrm{and} \mathrm{drafting} \mathrm{the} \mathrm{article.}$

\section{References}

Abel S, Hundhausen C, Mentlein R, Schulte A, Berkhout TA, Broadway N, Hartmann D, Sedlacek R, Dietrich S \& Muetze B 2004 The transmembrane CXC-chemokine ligand 16 is induced by IFN- $\gamma$ and TNF- $\alpha$ and shed by the activity of the disintegrin-like metalloproteinase ADAM10. Journal of Immunology 172 6362-6372. (doi:10.4049/jimmunol.172.10.6362)

Ahn SH, Henderson Y, Kang Y, Chattopadhyay C, Holton P, Wang M, Briggs K \& Clayman GL 2008 An orthotopic model of papillary thyroid carcinoma in athymic nude mice. Archives of Otolaryngology-Head \& Neck Surgery 134 190-197. (doi:10.1001/archoto.2007.36)

Ahn HY, Chung YJ, Kim BS, Kang KH, Seok JW, Kim HS, Park SJ \& Cho BY 2014 Clinical significance of the BRAF V600E mutation in multifocal papillary thyroid carcinoma in Korea. Surgery 155 689-695. (doi:10.1016/j.surg.2013.12.025)

Bingle L, Brown NJ \& Lewis CE 2002 The role of tumour-associated macrophages in tumour progression: implications for new anticancer therapies. Journal of Pathology 196 254-265. (doi:10.1002/path.1027)

Cho SW 2013 Interactions between immune cells and tumor cells. Journal of Korean Thyroid Association 6 96-100. (doi:10.11106/jkta.2013. 6.2.96)

Cho SW, Kim YA, Sun HJ, Ahn HY, Lee EK, Yi KH, Oh BC, Park do J, Cho BY \& Park YJ 2014 Therapeutic potential of Dickkopf-1 in wild-type BRAF papillary thyroid cancer via regulation of $\beta$-catenin/E-cadherin signaling. Journal of Clinical Endocrinology and Metabolism 99 E1641-E1649. (doi:10.1210/jc.2013-4467)

Colvin EK 2014 Tumor-associated macrophages contribute to tumor progression in ovarian cancer. Frontiers in Oncology 4 137. (doi:10.3389/ fonc.2014.00137)

Cunha LL, Morari EC, Guihen AC, Razolli D, Gerhard R, Nonogaki S, Soares FA, Vassallo J \& Ward LS 2012 Infiltration of a mixture of immune cells may be related to good prognosis in patients with differentiated thyroid carcinoma. Clinical Endocrinology 77 918-925. (doi:10.1111/j.1365-2265.2012.04482.x)

Deng L, Chen N, Li Y, Zheng H \& Lei Q 2010 CXCR6/CXCL16 functions as a regulator in metastasis and progression of cancer. Biochimica et Biophysica Acta 1806 42-49. (doi:10.1016/j.bbcan.2010.01.004)

Fang W, Ye L, Shen L, Cai J, Huang F, Wei Q, Fei X, Chen X, Guan H, Wang W et al. 2014 Tumor-associated macrophages promote the metastatic potential of thyroid papillary cancer by releasing CXCL8. Carcinogenesis 35 1780-1787. (doi:10.1093/carcin/bgu060)

Funada Y, Noguchi T, Kikuchi R, Takeno S, Uchida Y \& Gabbert HE 2003 Prognostic significance of $\mathrm{CD}^{+}{ }^{+} \mathrm{T}$ cell and macrophage peritumoral infiltration in colorectal cancer. Oncology Reports 10 309-313. (doi:10.3892/or.10.2.309)

Gough PJ, Garton KJ, Wille PT, Rychlewski M, Dempsey PJ \& Raines EW 2004 A disintegrin and metalloproteinase 10-mediated cleavage and shedding regulates the cell surface expression of CXC chemokine ligand 16. Journal of Immunology 172 3678-3685. (doi:10.4049/ jimmunol.172.6.3678)

Gutwein P, Schramme A, Sinke N, Abdel-Bakky MS, Voss B, Obermuller N, Doberstein K, Koziolek M, Fritzsche F, Johannsen M et al. 2009 Tumoural CXCL16 expression is a novel prognostic marker of longer survival times in renal cell cancer patients. European Journal of Cancer $\mathbf{4 5}$ 478-489. (doi:10.1016/j.ejca.2008.10.023)

Jung Y, Kim JK, Shiozawa Y, Wang J, Mishra A, Joseph J, Berry JE, McGee S, Lee E, Sun H et al. 2013 Recruitment of mesenchymal stem cells into prostate tumours promotes metastasis. Nature Communications 41795. (doi:10.1038/ncomms2766)

Kim S, Cho SW, Min HS, Kim KM, Yeom GJ, Kim EY, Lee KE, Yun YG, Park do J \& Park YJ 2013 The expression of tumor-associated macrophages in papillary thyroid carcinoma. Endocrinology and Metabolism 28 192-198. (doi:10.3803/EnM.2013.28.3.192)

Lu Y, Wang J, Xu Y, Koch AE, Cai Z, Chen X, Galson DL, Taichman RS \& Zhang JC 2008 XCL16 functions as a novel chemotactic factor for prostate cancer cells in vitro. Molecular Cancer Research 6 546-554. (doi:10.1158/1541-7786.MCR-07-0277)

Ludwig A, Hundhausen C, Lambert MH, Broadway N, Andrews RC, Bickett DM, Leesnitzer MA \& Becherer JD 2005 Metalloproteinase inhibitors for the disintegrin-like metalloproteinases ADAM10 and ADAM17 that differentially block constitutive and phorbol 
ester-inducible shedding of cell surface molecules. Combinatorial Chemistry \& High Throughput Screening 8 161-171. (doi:10.2174/ 1386207053258488)

Mantovani A, Sozzani S, Locati M, Allavena P \& Sica A 2002 Macrophage polarization: tumor-associated macrophages as a paradigm for polarized M2 mononuclear phagocytes. Trends in Immunology 23 549-555. (doi:10.1016/S1471-4906(02)02302-5)

Meijer J, Ogink J, Kreike B, Nuyten D, de Visser KE \& Roos E 2008 The chemokine receptor CXCR6 and its ligand CXCL16 are expressed in carcinomas and inhibit proliferation. Cancer Research 68 4701-4708. (doi:10.1158/0008-5472.CAN-08-0482)

Mosser DM 2003 The many faces of macrophage activation. Journal of Leukocyte Biology 73 209-212. (doi:10.1189/jlb.0602325)

Murray PJ \& Wynn TA 2011 Protective and pathogenic functions of macrophage subsets. Nature Reviews. Immunology 11 723-737. (doi:10.1038/nri3073)

Ohno S, Suzuki N, Ohno Y, Inagawa H, Soma G \& Inoue M 2003 Tumorassociated macrophages: foe or accomplice of tumors? Anticancer Research 23 4395-4409.

Qing W, Fang WY, Ye L, Shen LY, Zhang XF, Fei XC, Chen X, Wang WQ, Li XY, Xiao JC et al. 2012 Density of tumor-associated macrophages correlates with lymph node metastasis in papillary thyroid carcinoma. Thyroid 22 905-910. (doi:10.1089/thy.2011.0452)

Ryder M, Ghossein RA, Ricarte-Filho JC, Knauf JA \& Fagin JA 2008 Increased density of tumor-associated macrophages is associated with decreased survival in advanced thyroid cancer. Endocrine-Related Cancer 15 1069-1074. (doi:10.1677/ERC-08-0036)

Ryder M, Gild M, Hohl TM, Pamer E, Knauf J, Ghossein R, Joyce JA \& Fagin JA 2013 Genetic and pharmacological targeting of CSF1/CSF1R inhibits tumor-associated macrophages and impairs BRAF-induced thyroid cancer progression. PLOS ONE 8 e54302. (doi:10.1371/journal. pone.0054302)

Schramme A, Abdel-Bakky MS, Kampfer-Kolb N, Pfeilschifter J \& Gutwein P 2008 The role of CXCL16 and its processing metalloproteinases ADAM10 and ADAM17 in the proliferation and migration of human mesangial cells. Biochemical and Biophysical Research Communications 370 311-316. (doi:10.1016/j.bbrc.2008.03.088)

Shiao SL, Ganesan AP, Rugo HS \& Coussens LM 2011 Immune microenvironments in solid tumors: new targets for therapy. Genes and Development 25 2559-2572. (doi:10.1101/gad.169029.111)

Tiainen S, Tumelius R, Rilla K, Hamalainen K, Tammi M, Tammi R, Kosma VM, Oikari S \& Auvinen P 2015 High numbers of macrophages, especially M2-like (CD163-positive), correlate with hyaluronan accumulation and poor outcome in breast cancer. Histopathology $\mathbf{6 6}$ 873-883. (doi:10.1111/his.12607)

Wente MN, Gaida MM, Mayer C, Michalski CW, Haag N, Giese T, Felix K, Bergmann F, Giese NA \& Friess H 2008 Expression and potential function of the CXC chemokine CXCL16 in pancreatic ductal adenocarcinoma. International Journal of Oncology 33 297-308. (doi:10.3892/ijo_00000009)

Yuan ZY, Luo RZ, Peng RJ, Wang SS \& Xue C 2014 High infiltration of tumor-associated macrophages in triple-negative breast cancer is associated with a higher risk of distant metastasis. OncoTargets and Therapy 7 1475-1480. (doi:10.2147/OTT.S61838)

Zhou Q, Peng RQ, Wu XJ, Xia Q, Hou JH, Ding Y, Zhou QM, Zhang X, Pang ZZ, Wan DS et al. 2010 The density of macrophages in the invasive front is inversely correlated to liver metastasis in colon cancer. Journal of Translational Medicine 8 13. (doi:10.1186/1479-5876-8-13)

Received in final form 4 November 2015

Accepted 11 November 2015

Made available online as an Accepted Preprint

11 November 2015
(C) 2016 Society for Endocrinology Printed in Great Britain 